\title{
Serpentinization of the oceanic lithosphere and regulation of the Earth's water cycle
}

\author{
Julia Ribeiro ${ }^{1}$, YANG LiaO ${ }^{2}$, XiNLEI SuN ${ }^{1}$, JiAn LiN ${ }^{2}$, \\ JEFF RYAN ${ }^{3}$ \\ ${ }^{1}$ Guangzhou Institute of Geochemistry, The Chinese \\ Academy of Sciences, China \\ ${ }^{2}$ Woods Hole Oceanographic Institution, USA \\ ${ }^{3}$ University of South Florida, USA
}

Subduction zones have modulated the exchanges in water between the atmosphere, the oceans and the interior of the Earth over geological times. The serpentinized mantle that enters the trenches is thought to be one of the major water carriers within the deep Earth, as it can retain up to $13 \mathrm{wt} \%$ lattice-bound water. Yet, the extent to which this subducted, lithospheric mantle is hydrated and can transport mineralbounded water at and beyond the depth of arc magma generation is still unknown.

Here we seek to quantify the maximum flux of water that can be transported by the subducted serpentinized mantle into the deep interior of the Earth, and to discern whether this incoming water flux is balanced by the water outflux released via arc and back-arc magmatism. For this, we use a half-space cooling model and isostasy to place new constraints on how much serpentinite-bounded water can be carried in the lithospheric mantle prior to its subduction at the Cascadia and Mariana Trenches (i.e., typical end-members for hot and cold subduction zones, respectively). We find that the serpentinized mantle must be restricted to a thin layer (assuming $100 \%$ serpentinization) within the Pacific lithosphere to permit its sinking. Our new estimates suggest that the water outflux released during subduction zone volcanism could exceed the water influx transported down the Mariana Trench. If most subducted seawater is returned to the surface by subduction zone magmatism, we must consider the possibility that an additional water reservoir might be required to compensate for the water imbalances in some subduction systems [1]. In Cascadia, the subducted Pacific plate can carry more water to depths than previously estimated, implying that some intra-slab water could bypass the arc front. We further explore the implications of these new results for the origins and the pathways of recycled subducted seawater, beyond the depths of generation of subduction zone magmas.

1. Ribeiro, J. and C.T.A. Lee, EPSL, 2017. 